\title{
Decomposition of old organic matter as a result of deeper active layers in a snow depth manipulation experiment
}

\author{
Nicole S. Nowinski $\cdot$ Lina Taneva $\cdot$ \\ Susan E. Trumbore $\cdot$ Jeffrey M. Welker
}

Received: 29 October 2008/Accepted: 18 December 2009/Published online: 19 January 2010

(C) The Author(s) 2010. This article is published with open access at Springerlink.com

\begin{abstract}
A snow addition experiment in moist acidic tussock tundra at Toolik Lake, Alaska, increased winter snow depths 2-3 m, and resulted in a doubling of the summer active layer depth. We used radiocarbon $\left(\Delta^{14} \mathrm{C}\right)$ to (1) determine the age of $\mathrm{C}$ respired in the deep soils under control and deepened active layer conditions (deep snow drifts), and (2) to determine the impact of increased snow and permafrost thawing on surface $\mathrm{CO}_{2}$ efflux by partitioning respiration into autotrophic and heterotrophic components. $\Delta^{14} \mathrm{C}$ signatures of surface respiration were higher in the deep snow areas, reflecting a decrease in the proportion of autotrophic respiration. The radiocarbon age of soil pore $\mathrm{CO}_{2}$ sampled near the maximum mid-July thaw depth was approximately 1,000 years in deep snow
\end{abstract}

Communicated by Dan Yakir.

Electronic supplementary material The online version of this article (doi:10.1007/s00442-009-1556-x) contains supplementary material, which is available to authorized users.

N. S. Nowinski $(\bowtie) \cdot$ S. E. Trumbore

Department of Earth System Science, University of California,

Irvine, 3200 Croul Hall, Irvine, CA 92697, USA

e-mail: nnowinsk@alumni.uci.edu; nowinskn@gmail.com

L. Taneva $\cdot$ J. M. Welker

Environment and Natural Resources Institute,

University of Alaska, Anchorage,

707 A St, Anchorage, AK 99501, USA

J. M. Welker

Biology Department, University of Alaska, Anchorage,

3211 Providence Dr, ENGR 333, Anchorage, AK 99508, USA

Present Address:

S. E. Trumbore

Max-Planck Institute for Biogeochemistry,

Hans-Knoell Strasse 10, 07745 Jena, Germany treatment plots $\left(45-55 \mathrm{~cm}\right.$ thaw depth), while $\mathrm{CO}_{2}$ from the ambient snow areas was $\sim 100$ years old $(30-\mathrm{cm}$ thaw depth). Heterotrophic respiration $\Delta^{14} \mathrm{C}$ signatures from incubations were similar between the two snow depths for the organic horizon and were extremely variable in the mineral horizon, resulting in no significant differences between treatments in either month. Radiocarbon ages of heterotrophically respired $\mathrm{C}$ ranged from $<50$ to 235 years $\mathrm{BP}$ in July mineral soil samples and from 1,525 to 8,300 years BP in August samples, suggesting that old soil $\mathrm{C}$ in permafrost soils may be metabolized upon thawing. In the surface fluxes, this old $\mathrm{C}$ signal is obscured by the organic horizon fluxes, which are significantly higher. Our results indicate that, as permafrost in tussock tundra ecosystems of arctic Alaska thaws, carbon buried up to several thousands of years ago will become an active component of the carbon cycle, potentially accelerating the rise of $\mathrm{CO}_{2}$ in the atmosphere.

Keywords Permafrost - Arctic · Tundra . Carbon cycling $\cdot$ Radiocarbon

\section{Introduction}

Thawing permafrost, as evidenced by thermokarst formation (Jorgenson et al. 2001, 2006) and observations of warmer permafrost temperatures across the arctic (Osterkamp and Romanovsky 1999), is one of the most important climate feedback concerns today (Romanovsky and Osterkamp 2000; IPCC 2007; Ping et al. 2008; Schuur et al. 2009) This carbon (C) pool contains 250-455 Pg of C (Miller et al. 1983; Post et al. 1985; Gorham 1991) that, upon thawing, may be released as $\mathrm{CO}_{2}$ and $\mathrm{CH}_{4}$ (McKane et al. 1997; Ping et al. 2008) or as dissolved organic C 
(Neff et al. 2006), creating a major positive feedback scenario. Today, with the arctic warming at least $0.5^{\circ} \mathrm{C}$ per decade (Serreze et al. 2000), there is a strong likelihood that permafrost will become an increasingly important source of $\mathrm{C}$ to the atmosphere, as active layers deepen, soils warm and microbial degradation of ancient organic matter releases $\mathrm{CO}_{2}$ and nutrients (Schuur et al. 2008). For instance, recent estimates indicate that up to $40 \mathrm{Pg}$ of $\mathrm{C}$ may be released to the atmosphere due to thawing in Siberia over the next 40 years (Dutta et al. 2006). However, the magnitude of this release may be ameliorated by the stimulation of vegetation growth by nutrients released during thaw, particularly in the early stages (Schuur et al. 2009).

Tundra field experiments have focused primarily on quantifying the extent to which changes in summer conditions (warmer air and soil, added fertilizer, reduced light, added water) alter $\mathrm{C}$ biogeochemistry and feedback dynamics (Chapin and Shaver 1985; Welker et al. 1993, 1999, 2000, 2004, 2006; Wookey et al. 1993; Chapin et al. 1995, 2005; Robinson et al. 1995; Shaver et al. 1998; Callaghan et al. 2004; Mack et al. 2004; Aerts et al. 2007). However, it is now becoming increasingly clear that changes in winter snow depth may have direct and indirect effects on winter soil $\mathrm{CO}_{2}$ efflux (e.g., Welker et al. 2000), soil $\mathrm{C}$ and $\mathrm{N}$ mineralization (Schimel et al. 2004; Borner et al. 2008), and subsequent effects on annual $\mathrm{C}$ budgets and summer leaf mineral nutrition (Welker et al. 2005), culminating in shifts in tundra vegetation composition and canopy structure (Sturm et al. 2005; Wahren et al. 2005; Tape et al. 2006).

Deep snowpacks $(\sim 3 \mathrm{~m})$ insulate soil from cold wintertime atmospheric temperatures, resulting in warmer soil temperatures and increased summer thaw, as well as shortening the growing season by up to 3 weeks (Wahren et al. 2005). Recently, we have observed that, after 13 years of experimental snow pack manipulations (Welker et al. 2005), the soil active layer under the deep snow treatment has doubled as a result of permafrost thawing (Fig. 1). In order to better understand the effects of winter snow manipulation and increased active layer depth on soil $\mathrm{C}$ storage and turnover, we used radiocarbon measurements of $\mathrm{CO}_{2}$ to determine the age of $\mathrm{C}$ respired by microbes and to partition surface $\mathrm{CO}_{2}$ efflux into autotrophic and heterotrophic sources of respiration. Radiocarbon allows us to understand $\mathrm{C}$ turnover on annual to millennial timescales. Conventional radiocarbon dating is used to determine ages of preserved organic materials on centennial to millennial timescales, while tracking the fate of radiocarbon from nuclear weapons testing in the mid-twentieth century can be used to ascertain turnover times on annual to decadal timescales (Broecker and Peng 1982).
This study was designed to address two questions: (1) is the $\Delta{ }^{14} \mathrm{C}$ of microbial respiration in areas with permafrost thawing (deep winter snow) significantly different than areas without experimental thawing (ambient snow depth); and (2) are changes in vegetation cover or microbial respiration in response to snow depth manipulation evident in the radiocarbon signatures of the surface $\mathrm{CO}_{2}$ flux?

\section{Materials and methods}

Study sites

A $3 \times 60 \mathrm{~m}$ snow fence was erected in 1994 , in moist acidic tussock tundra at Toolik Lake, Alaska $\left(68^{\circ} 38^{\prime} \mathrm{N}\right.$, $\left.149^{\circ} 34^{\prime} \mathrm{W}\right)$, in the foothills of the Brooks Range $(760 \mathrm{~m})$ as part of the International Tundra Experiment (Henry and Molau 1997; Welker et al. 1997). This fence has allowed an additional 2-3 $\mathrm{m}$ of snow to accumulate each winter within $20 \mathrm{~m}$ of the leeward side of the fence (Walker et al. 1999), shortening the growing season by $2-3$ weeks (Jones et al. 1998; Welker et al. 2000, 2005; Wahren et al. 2005) and increasing permafrost thaw an extra $30 \mathrm{~cm}$ by the end of the growing season (Fig. 1). One important consequence of this constrained growing season is that vegetation cover has been reduced by $50 \%$ and total live aboveground biomass of Eriophorum vaginatum and Betula nana has been reduced from 550 to $100 \mathrm{gm}^{-2}$ (Welker et al., unpublished data). Future climate scenarios do not predict a snow depth increase of this magnitude, consequently the aim of this study is to examine the effects of permafrost thaw.

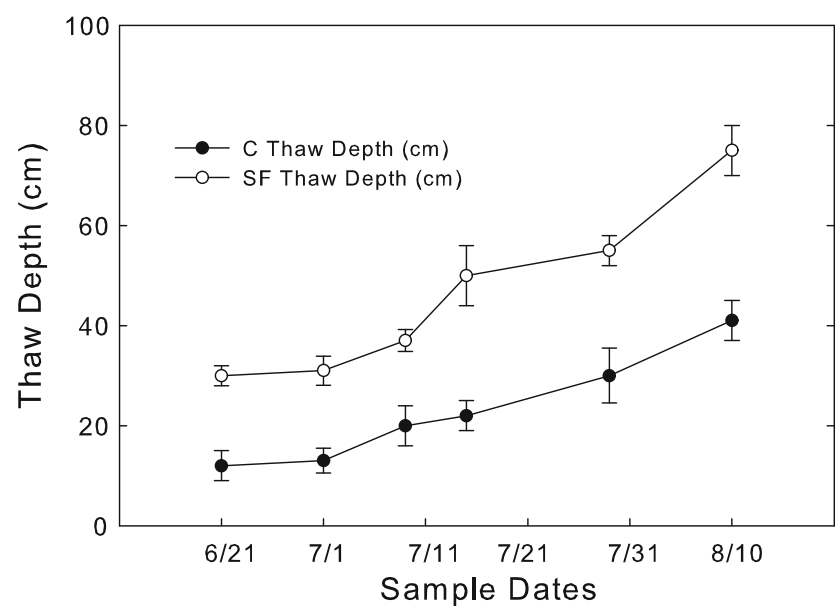

Fig. 1 Mean thaw depth $( \pm \mathrm{SE})$ in the ambient snow control depth $(C \sim 50 \mathrm{~cm})$ and the deep snow depth (snow fence, $S F \sim 300 \mathrm{~cm}$ ) zones between June and August 2005. Five intertussock locations in each zone over a 30-m transect were measured using an incremented stainless steel rod 
Field methods

\section{Total (autotrophic + heterotrophic) respiration sampling}

Our samples were derived from two areas, the snow fence area (SF) (deep winter snow depth $\sim 3 \mathrm{~m}$ ) area behind the snow fence and the ambient snow control $(\mathrm{C})$ areas (winter snow depth $\sim 50 \mathrm{~cm}$ ). In early July 2007 , eight $25-\mathrm{cm}-$ diameter PVC collars were installed per treatment into the soil to a depth of approximately $10 \mathrm{~cm}$ (including litter/ moss). In mid-July and mid-August, four collars with a representative mix of vegetation were capped using opaque lids fitted with a rubber closed cell foam gasket in each treatment, resulting in chamber height of $10-15 \mathrm{~cm} . \mathrm{CO}_{2}$ was scrubbed from the chambers using soda lime, preceded by a Drierite column, and then $\mathrm{CO}_{2}$ was allowed to accumulate for approximately 30-60 min until there was at least $2 \mathrm{mg}$ of $\mathrm{C}$ in the chamber as determined by previously measured respiration rates. This $\mathrm{CO}_{2}$ was then collected and saved using molecular sieve traps (preceded by Drierite columns to prevent the sorbtion of water), which release $\mathrm{CO}_{2}$ when heated to $\sim 600^{\circ} \mathrm{C}$. At the same time, a sample of atmospheric $\mathrm{CO}_{2}$ was also obtained. One collar in the July $\mathrm{C}$ treatment was excluded from subsequent analysis due to air contamination.

\section{Soil pore $\mathrm{CO}_{2}$ sampling}

Gas sampling tubes were installed in mid-July near the maximum thaw depth at that time, four in the control plots, where the thaw depth was $\sim 30 \mathrm{~cm}$, and four in the treatment plots, where the maximum thaw depth was 45$55 \mathrm{~cm}$. The maximum thaw depths in July 2007 were greater than the average for that time of year. One gas sample from each probe was obtained in July by slowly filling pre-evacuated canisters and brought back to the laboratory for $\Delta^{14} \mathrm{C}$ analysis (Gaudinski et al. 2000). One sample from the control and two from the treatment plots contained too much water to be analyzed.

\section{Soil collection}

Soils were collected in mid-July and mid-August within 23 days of the field respiration measurements. Four cores were collected from the surface of the organic horizon to the top of the permafrost in each treatment using a $5.5-\mathrm{cm}-$ diameter corer (live surface vegetation was excluded except moss, as it was difficult to separate living and dead portions). They were frozen after collection and thawed just prior to heterotrophic respiration and $\mathrm{C}$ content analysis. After transport to the laboratory, soil core samples were thawed and divided into two layers representing the litter/organic and mineral horizons.
Laboratory methods

\section{Heterotrophic respiration incubations}

Organic and mineral soils were put into separate glass incubation jars for heterotrophic respiration analysis (four per horizon/treatment). Organic soils (including litter) were only measured from the July sampling, as the respiration rates and signatures should not change (Czimczik et al., 2006). $\mathrm{CO}_{2^{-}}$ free air was pumped into the jars, after which they were sealed, stored in darkness at $7^{\circ} \mathrm{C}$, and $\mathrm{CO}_{2}$ from the soils was allowed to accumulate. For a 1-week period, $\mathrm{CO}_{2}$ concentrations were measured daily using a Licor 6252 Infrared Gas Analyzer and average respiration rates were calculated (Davidson and Trumbore 1995). Air in the jars was replaced with $\mathrm{CO}_{2}$-free air whenever $\mathrm{CO}_{2}$ concentrations exceeded $3 \%$. At the end of a 2-week period, the $\mathrm{CO}_{2}$ in the jars was collected into evacuated canisters and stored until extraction (Dioumaeva et al. 2002; Czimczik et al. 2006).

To establish a relationship between $\mathrm{CO}_{2}$ evolution rate and temperature, the temperature of incubation for half the July jars was increased to $15^{\circ} \mathrm{C}$ and rates were measured as above (Dioumaeva et al. 2002; Czimczik et al. 2006). The rates were then used to calculate separate $\mathrm{Q}_{10} \mathrm{~s}$ for the organic and mineral horizons using the equation:

$Q_{10}=\left(\frac{R_{2}}{R_{1}}\right)^{\left(\frac{10}{T_{2}-T_{1}}\right)}$

These functions were combined with temperature profiles to estimate the contribution to surface fluxes (Dioumaeva et al. 2002; Czimczik et al. 2006).

Following incubation, soil cores were dried at $60^{\circ} \mathrm{C}$ for several days, and the difference in weight was used to calculate the gravimetric moisture content.

\section{Partitioning calculations and corrections}

Low fluxes and leaks in chambers meant that trapped samples included air that entered the chambers following the scrubbing procedure. In order to correct for air in the field respiration samples, the typical $\delta^{13} \mathrm{C}$ signatures of $\mathrm{C}_{3}$ vegetation $\left(\delta^{13} \mathrm{C}_{\text {samp }}\right)$, the atmosphere $\left(\delta^{13} \mathrm{C}_{\text {air }}\right)$, and the measured value $\left(\delta^{13} \mathrm{C}_{\text {meas. }}\right)$ were used to calculate the air fraction $\left(\mathrm{F}_{\text {air }}\right)$ using a mass balance equation.

$\delta^{13} \mathrm{C}_{\text {air }}\left(F_{\text {air }}\right)+\delta^{13} \mathrm{C}_{\text {samp. }}\left(1-F_{\text {air }}\right)=\delta^{13} \mathrm{C}_{\text {meas. }}$,

where $\delta^{13} \mathrm{C}_{\text {air }}=-8 \%$ o, $\delta^{13} \mathrm{C}_{\text {samp. }}=-24 \%$.

Subsequently, the air fraction, the atmospheric $\Delta^{14} \mathrm{C}$ signature $\left(\Delta^{14} \mathrm{C}_{\text {air }}\right)$ and the measured $\Delta^{14} \mathrm{C}$ signature $\left(\Delta{ }^{14} \mathrm{C}_{\text {meas }}\right.$ ), were used to determine the $\Delta^{14} \mathrm{C}$ signature of the $\mathrm{CO}_{2}$ derived from surface respiration $\left(\Delta^{14} \mathrm{C}_{\text {samp. }}\right)$. Samples were excluded when $F_{\text {air }}$ exceeded 0.5. 
$\Delta{ }^{14} \mathrm{C}_{\text {air }}\left(F_{\text {air }}\right)+\Delta \Delta^{14} \mathrm{C}_{\text {samp. }}\left(1-F_{\text {air }}\right)=\Delta \Delta^{14} \mathrm{C}_{\text {meas. }}$

where $\Delta{ }^{14} \mathrm{C}_{\text {air }}$ was $50 \%$ o $( \pm 1 \%$ ) based on three air samples collected at the time of field respiration measurement.

Finally, the proportion of $\mathrm{C}$ derived from autotrophic respiration was calculated using the following equation:

$\Delta \Delta^{14} \mathrm{C}_{\mathrm{air}}\left(F_{\mathrm{AR}}\right)+\Delta \Delta^{14} \mathrm{C}_{\mathrm{HR}}\left(1-F_{\mathrm{AR}}\right)=\Delta \Delta^{14} \mathrm{C}_{\text {sample }}$

where $F_{\mathrm{AR}}$ is the fraction of autotrophic respiration and $\Delta{ }^{14} \mathrm{C}_{\mathrm{HR}}$ is the average flux-weighted radiocarbon signature of heterotrophic respiration (July) derived from incubations, using fluxes that were temperature corrected to $3^{\circ} \mathrm{C}$ for the organic and $1{ }^{\circ} \mathrm{C}$ for the mineral soil layers using $\mathrm{Q}_{10} \mathrm{~s}$. Autotrophic respiration is generally made up of recent photosynthates; therefore, it was assumed to have atmospheric $\Delta^{14} \mathrm{C}$ values but $\mathrm{C}_{3}$ plant $\delta^{13} \mathrm{C}$ values (Ekblad and Högberg 2001). The heterotrophic respiration values measured from soil cores were extremely variable, consequently an average of the July incubations was used as the end member for each respective treatment. Field measurements likely show less spatial variability because the area measured by one sample is equivalent to 20 soil cores, consequently the average is the most realistic representation of the heterotrophic respiration component. The July heterotrophic respiration value was used for partitioning in both cases, as the flux of old $\mathrm{C}$ from the deep soils was likely overestimated in the August incubations to a greater degree. Additionally, it is not clear whether $\mathrm{CO}_{2}$ from the very deep soils would leave via the atmosphere or dissolved in water under natural conditions.

\section{$C$ contents of soils}

C contents were analyzed on soil cores taken in August at the same time as the cores used for incubation were collected. After thawing, sub-samples were taken every $10 \mathrm{~cm}$ down the depth of each of the three cores per treatment and analyzed for $\% \mathrm{C}$ in a Costech elemental analyzer.

\section{$\Delta^{14} \mathrm{C}$ Measurements}

In the laboratory, $\mathrm{CO}_{2}$ samples were purified cryogenically from air samples stored in canisters and from the molecular sieve traps by heating to $600^{\circ} \mathrm{C}$ to release the $\mathrm{CO}_{2}$. All $\mathrm{CO}_{2}$ was purified on a vacuum line and reduced to graphite using sealed tube zinc reduction with an iron catalyst $(\mathrm{Xu}$ et al. 2007). The graphite was then analyzed for ${ }^{14} \mathrm{C}$ and ${ }^{13} \mathrm{C}$ at the W.M. Keck AMS facility at UC-Irvine (Southon et al. 2004). $\Delta^{14} \mathrm{C}$ units are used to report these data, and are defined as:
$\Delta^{14} \mathrm{C}=\left[\frac{\left.{ }^{\frac{14}{12} \mathrm{C}}\right]_{\mathrm{sample},-25}}{\left.0.95 \frac{14}{{ }^{12} \mathrm{C}}\right]_{\mathrm{Ox} 1,-19} \exp ^{((2006-1950) / 8267)}}-1\right] 1000$

In other words, the deviation (in parts per thousand) of the ${ }^{14} \mathrm{C} /{ }^{12} \mathrm{C}$ ratio of the sample from that of Oxalic Acid I, the international standard, was corrected for radioactive decay of $\Delta^{14} \mathrm{C}$ between the year of sampling and 1950 using the real radiocarbon half-life (Stuiver and Polach 1977). $\Delta^{14} \mathrm{C}$ measurements do not reflect mass dependent fractionation, because samples were normalized to a $\delta^{13} \mathrm{C}$ of $-25 \%$, assuming $\Delta^{14} \mathrm{C}$ fractionation is twice that of $\delta^{13} \mathrm{C}$ (Southon et al. 2004). An aliquot of purified $\mathrm{CO}_{2}$ was retained and used for higher precision $\delta^{13} \mathrm{C}$ measurements made on a continuous flow stable isotope ratio mass spectrometer (Delta-Plus CFIRMS), operated in Gasbench mode.

Conventional radiocarbon ages (years BP) (Stuiver and Polach 1977) are reported on samples with $\Delta{ }^{14} \mathrm{C}$ less than $0 \%$ and were calculated with the following equation, which uses the Libby half-life (5,568 years) and 1950 as year 0 .

$t=-8033 \ln \left[\frac{\left.\frac{14 \mathrm{C}}{12 \mathrm{C}}\right]_{\mathrm{sample},-25}}{\left.0.95 \frac{14 \mathrm{C}}{12 \mathrm{C}}\right]_{\mathrm{OX} 1,-19}}\right]$

Prior to nuclear weapons testing and the advent of fossil fuel use, the atmospheric $\Delta{ }^{14} \mathrm{C}$ signature was approximately $0 \%$, although slight variations existed. $\Delta{ }^{14} \mathrm{C}$ signatures increased dramatically due to nuclear weapons testing in the mid-twentieth century and have subsequently been declining due to biological uptake and fossil fuel inputs $(-1000 \%)$. Samples with negative $\Delta^{14} \mathrm{C}$ values were fixed long enough prior to 1950 for significant radioactive decay of radiocarbon to have occurred; for these samples, we used the radiocarbon age. For $\mathrm{C}$ fixed since 1960, the highest $\Delta^{14} \mathrm{C}$ signatures are associated with decadally cycling carbon pools (i.e., most of the $\mathrm{C}$ was fixed closer in time to the 1960 s maximum in $\Delta{ }^{14} \mathrm{C}$ ), while the most recently fixed $\mathrm{C}$ will have values close to the 2007 atmosphere $(48 \%$ ).

\section{Statistics}

Statistical analyses were performed using SPSS statistical software. Group means were compared using $t$ tests. Standard deviations reported reflect spatial variability.

\section{Results}

The $\Delta^{14} \mathrm{C}$ signature of $\mathrm{CO}_{2}$ in soil pores in the deepened active layer area was significantly lower at the maximum 
July depth of thaw by up to $70 \%$ when compared to the control areas $(P=0.007, t$ test). In the deep snow (SF) area the $\Delta^{14} \mathrm{C}$ values averaged $-106 \% \pm 39 \mathrm{SD}(\sim 50 \mathrm{~cm}$ depth) versus $41 \% \pm 18 \mathrm{SD}$ (30 cm depth) in the control (C) area. This corresponds to mean ages of approximately $600-1,100$ years $\mathrm{BP}$ in the SF area compared to $<100$ years BP (i.e., containing 'bomb' radiocarbon) in the $\mathrm{C}$ areas.

Although permafrost thawing resulted in the decomposition of old $\mathrm{C}$ and the subsequent production of older $\mathrm{CO}_{2}$ in the soil profile, older $\mathrm{C}$ did not dominate the surface $\mathrm{CO}_{2}$ efflux (Fig. 2a). The radiocarbon values $\left(\Delta^{14} \mathrm{C}\right)$ of the surface $\mathrm{CO}_{2}$ efflux were on average $25 \%$ higher ( $P=0.034$, July; $P=0.038$, August) in the SF area than the $\mathrm{C}$ area (Fig. 2a). Because the heterotrophic fluxes are dominated by decadal-aged $\mathrm{C}$ (higher $\Delta^{14} \mathrm{C}$ ) and the autotrophic respiration is derived from recently fixed photosynthetic products (lower $\Delta \Delta^{14} \mathrm{C}$ ), the higher $\Delta{ }^{14} \mathrm{C}$ values in the SF area indicate that $\sim 60 \%$ of respiration (sample range 40-80\%) was derived from the vegetation in the $\mathrm{C}$ area and $\sim 27 \%$ (sample range $0-55 \%$ ) in the SF area (Fig. 2b).

Heterotrophic respiration rates were much higher in the organic soils than in the mineral soils and were particularly variable in the mineral soils (data not shown), but showed few other trends. There were no differences between treatments or months in the flux-weighted total heterotrophic respiration rates (org. + min., corrected for temperature) (data not shown). $\mathrm{Q}_{10} \mathrm{~s}$ in mineral soil tended to be higher than the organic soil, although they were also quite variable $\left(\mathrm{Q}_{10}=1.5 \pm 0.4\right.$, organic; $\mathrm{Q}_{10}=2.7 \pm 1.3$, mineral).

There were no differences between the permafrost thaw conditions in the $\Delta^{14} \mathrm{C}$ values of heterotrophic respiration from the organic layer (Fig. 3). The observed $\Delta^{14} \mathrm{C}$ values correspond to organic matter turnover times of 9-17 years in this horizon. These measurements were only made on the soils collected in July, as the results should not change between July and August (Czimczik et al. 2006).

Ages of heterotrophically respired $\mathrm{CO}_{2}$ from the mineral soil were modern $\left(\Delta^{14} \mathrm{C}>0 \%\right)$ in the control $(\mathrm{C})$ and modern-235 years BP in the SF soils in July (Fig. 3). Although some samples from the SF treatment respired $\mathrm{CO}_{2}$ with $\Delta{ }^{14} \mathrm{C}<0 \%$ (i.e., pre- 1950 values), the means between treatments were not significantly different. In August, $\mathrm{C}$ respired from the mineral soil-which integrated a deeper thaw depth in both treatments-was older than in the July samples $\left(P<0.001, t\right.$ test $\left.\Delta{ }^{14} \mathrm{C}\right)$, with the $\Delta{ }^{14} \mathrm{C}$ ages ranging from 1,720 to 5,960 years $\mathrm{BP}$ in the control areas and from 1,525 to 8,300 years in the $\mathrm{SF}$ areas. There was no relationship between $\Delta^{14} \mathrm{C}$ and thaw depth in August, despite substantial differences in thaw depth. C contents were variable and showed few trends (Fig. 4), and
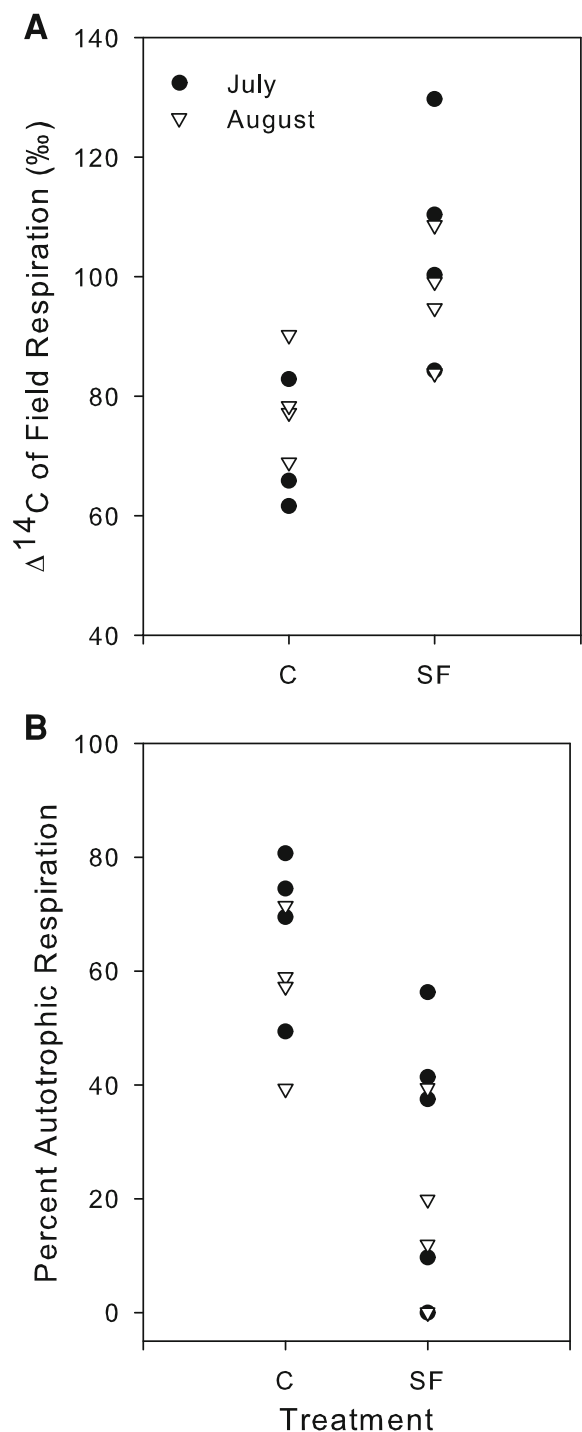

Fig. 2 a $\Delta^{14} \mathrm{C}$ of field respiration. Black circles represent July measurements and white triangles represent August. $S F$ refers to the snow fence treatment and $C$ refers to the control. b Percent of field respiration from autotrophic sources. Black circles represent July measurements and white triangles represent August. Heterotrophic respiration ${ }^{14} \mathrm{C}$ signatures from July incubations were used for both July and August field measurement dates. Autotrophic respiration was assumed to be similar to the 2007 atmosphere

there were no significant differences between treatments. There appeared to be an increase in $\mathrm{C}$ contents with depth in the deeper soils, although this was not linear.

\section{Discussion}

At the surface, total (autotrophic + heterotrophic) $\mathrm{C}$ fluxes were dominated by $\mathrm{C}$ fixed $1950-$ present $\left(>0 \% \Delta^{14} \mathrm{C}\right)$ (Fig. 2a). Autotrophic respiration was responsible for a smaller fraction of total respiration in the SF areas 


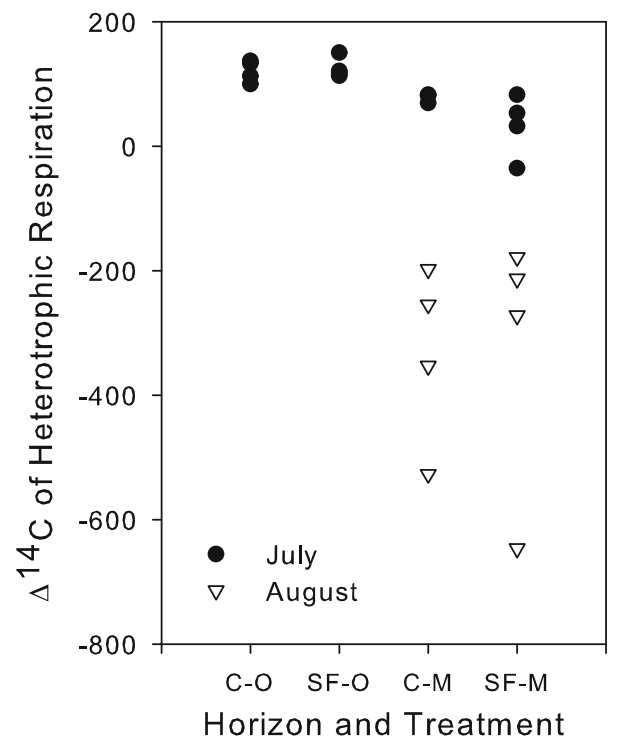

Fig. $3 \Delta \Delta^{14} \mathrm{C}$ of heterotrophic soil respiration incubations. Black circles represent July measurements and white triangles represent August. $O$ indicates organic soil incubations and $M$ indicates mineral soil incubations, while $S F$ indicates cores derived from the deep snow area and $C$ refers to samples taken from the ambient snow areas

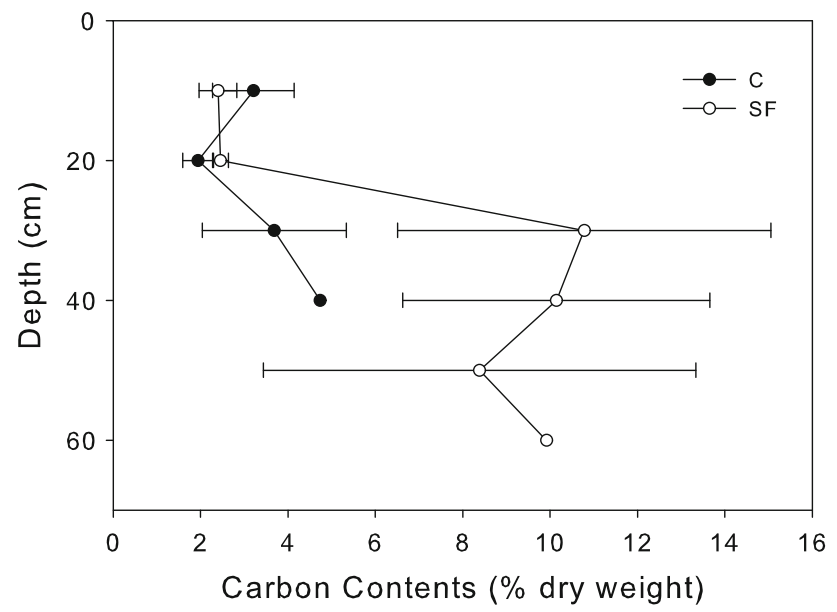

Fig. 4 Soil C content profile. A soil sub-sample was taken from 3 soil cores per treatment approximately every $10 \mathrm{~cm}$ and analyzed for $\mathrm{C}$. $S F$ refers to cores from the snow fence area and $C$ refers to cores from the control area. Error bars depict standard error

(Fig. 2b), which could reflect either increased heterotrophic or decreased autotrophic respiration fluxes. Weighted heterotrophic respiration fluxes were dominated by the organic horizon and did not appear to change with the depth of permafrost thaw (data not shown). Therefore, the difference between treatments likely reflects a reduction in the autotrophic component in the increased snow treatment, which had a shortened growing season and less vegetation cover where snow depths were greatest (Walker et al. 1999; Wahren et al. 2005). Debris also accumulates in the deep drift region and is associated with reduced photosynthetically active radiation, possibly interfering with autotrophic plant activity (Fahnestock et al. 2000).

July soil pore $\Delta^{14} \mathrm{CO}_{2}$ values indicate $\mathrm{C}$ aged 600 1,100 years BP was being decomposed in the SF area soil profile, at least 8 times older than the $\mathrm{C}$ in soil pores from the $\mathrm{C}$ areas. July heterotrophic respiration measurements did not reflect the influence of this older $\mathrm{CO}_{2}$ at depth, likely because soil pore gas measurements were taken at the maximum thaw depth, which was $15-25 \mathrm{~cm}$ deeper than the average thaw depth represented in our soil core samples. Older $\mathrm{C}$ was not detectable in the soil surface respiration measurements in either treatment, due primarily to the overwhelming fluxes associated with plants and heterotrophic respiration fluxes from the organic horizon. Increased efflux from mineral soils could be detected at the surface if respiration rates from these depths were similar to the highest individual rates observed in our (isothermal $7^{\circ} \mathrm{C}$ ) incubations; however, we did not observe this in the field. This may be because the $\mathrm{C}$ is not escaping via the surface flux route or because these rates are unrealistic in the field. Laboratory incubations result in changes in moisture regimes, which may increase respiration and the lack of temperature gradients in the laboratory result in the over-representation of respiration from the deep soils. It is also possible that thawing exposes small pockets of $\mathrm{C}$ that have very high decomposition rates, which may dominate a small sample (i.e., a soil core), but not a large one (i.e., a surface flux measurement). Despite all of this, it is clear from the soil pore gas results that some old $\mathrm{C}$ is respired at depth, although perhaps less than would be estimated by extrapolating incubation measurements directly to field conditions.

Our observation that the oldest ages of respired $\mathrm{CO}_{2}$ occurs at depth in mineral soils is not surprising. Measurements of heterotrophic respiration of the deeper mineral soils would be expected to be older than the shallower soils. Incubations of mineral soil samples taken in July showed that the $\mathrm{C}$ respired was mostly $>0 \% \Delta^{14} \mathrm{C}$, indicating the presence of post-bomb carbon. However, in August, when mineral soils were thawed to greater depths, the samples were much older, suggesting there was indeed a relationship between thaw depth and age of $\mathrm{C}$ respired, but not a linear one (Fig. 3). The lack of a linear relationship may be due to cryoturbation, which results in soils that are very heterogeneous both in terms of $\mathrm{C}$ contents and decomposability (Fig. 4) (Bockheim and Tarnocai 1998). Other studies suggest that this mechanism is extremely common and is likely to result in the high spatial heterogeneity observed in $\mathrm{C}$ stocks observed in tussock tundra (Michaelson et al. 1996; Bockheim 2007).

Although this was a small study with limited statistical power, these findings indicate that exposing long frozen $\mathrm{C}$ to thawing has the potential to allow very old $\mathrm{C}$ to be 
decomposed, potentially accelerating the rate of $\mathrm{CO}_{2}$ increase in the atmosphere. Our findings complement those recently reported by Schuur et al. (2009). In their study of tussock tundra near Denali National Park, they find C exceeding 1,000 years BP is being lost from sites with degrading permafrost, the magnitude of this loss being dependent upon the time since thawing begun. Early on, total $\mathrm{C}$ sequestration increases due to increases in soil nutrient pools and the stimulation of plant growth. However, as the period of degradation increases, respiration losses increase and the landscapes become net $\mathrm{C}$ sources to the atmosphere. As with this study, old, deep $\mathrm{C}$ mobilized by thaw is a relatively minor contribution to surface fluxes.

These findings suggest that while large $\mathrm{C}$ stocks exist in permafrost soil (Miller et al. 1983; Post et al. 1985; Gorham 1991), upon thaw, they will initially contribute only a minor amount of $\mathrm{CO}_{2}$ to atmosphere relative to overall fluxes. However, as the area of thawed soil increases, along with nutrient availability, permafrost $\mathrm{C}$ will become an increasingly important $\mathrm{CO}_{2}$ source, although the future fluxes will depend on the interaction of biology with physical changes in the soil due to warming. Differences in $\mathrm{C}$ losses are not discernable at the surface due to the overwhelming influence of the organic horizon and plant respiration; however, it is clear that very old $\mathrm{C}$ at depth is labile and, when exposed to thawing, can be metabolized. How much $\mathrm{C}$ will be metabolized depends mainly on the thaw depth, the amount and composition of organic $\mathrm{C}$ stored in currently frozen soil, and physical changes in the soil environment. Although C losses from deep permafrost soils appear to be insignificant in the short term, the cumulative $C$ loss due to decades of thawing is likely to have a significant impact on the global $\mathrm{C}$ cycle.

Acknowledgments We thank Toolik Long Term Ecological Research Station for logistical field support, Jeremy Chingell for field assistance, and Claudia Czimczik, Monica Castenada, Matt Khosh, and Xiaomei $\mathrm{Xu}$ for laboratory assistance. This research was supported by NSF OPP grants 0632184 and 0612534 awarded to J.M.W. and the WM Keck Carbon Cycle AMS Facility. This experiment complied with all laws of the United States.

Open Access This article is distributed under the terms of the Creative Commons Attribution Noncommercial License which permits any noncommercial use, distribution, and reproduction in any medium, provided the original author(s) and source are credited.

\section{References}

Aerts R, Cornelissen JHC, van Logtestijn RSP, Callaghan TV (2007) Climate change has only a minor impact on nutrient resorption parameters in a high-latitude peatland. Oecologia 151:132-139
Bockheim JG, Tarnocai C (1998) Recognition of cryoturbation for classifying permafrost-affected soils. Geoderma 81:281-293

Bockheim JG (2007) Importance of cryoturbation in redistributing organic carbon in permafrost-affected soils. Soil Sci Soc Am J $71: 1335-1342$

Borner AP, Kielland K, Walker MD (2008) Effects of simulated climate change on plant phenology and nitrogen mineralization in Alaskan arctic tundra. Arct Antarct Alp Res 40:27-38

Broecker W, Peng T (1982) Tracers in the sea. Columbia University Press, New York

Callaghan TV, Björn LO, Chernov Y, Chapin FS, Christensen TR, Huntley B, Ims RA, Johansson M, Jolly D, Jonasson S, Matveyeva N, Panikov N, Oechel WC, Shaver GR, Elster J, Henttonen H, Jonsdottir IS, Laine K, Schaphoff S, Sitch S, Taulavuori K, Taulavuori E, Zöckler C (2004) Climate change and UV-B impacts on Arctic Tundra and Polar desert ecosystems: key findings and extended summaries. Ambio 33(7):386392

Chapin FS, Shaver GR (1985) Individualistic growth-response of tundra plant-species to environmental manipulations in the field. Ecology 66:564-576

Chapin FS, Shaver GR, Giblin AE, Nadelhoffer KJ, Laundre JA (1995) Responses of arctic tundra to experimental and observed changes in climate. Ecology 76:694-711

Chapin FS et al (2005) Role of land-surface changes in arctic summer warming. Science 310:657-660

Czimczik CI, Trumbore SE, Carbone MS, Winston GC (2006) Changing sources of soil respiration with time since fire in a boreal forest. Glob Change Biol 12:957-971

Davidson EA, Trumbore SE (1995) Gas diffusivity and production of CO2 in deep soils of the eastern Amazon. Tellus B Chem Phys Meteorol 47:550-565

Dioumaeva I, Trumbore S, Schuur EAG, Goulden ML, Litvak M, Hirsch AI (2002) Decomposition of peat from upland boreal forest: temperature dependence and sources of respired carbon. $\mathrm{J}$ Geophys Res Atmos 108:8222

Dutta K, Schuur EAG, Neff JC, Zimov SA (2006) Potential carbon release from permafrost soils of Northeastern Siberia. Glob Change Biol 12:2336-2351

Ekblad A, Högberg P (2001) Natural abundance of C-13 in $\mathrm{CO}_{2}$ respired from forest soils reveals speed of link between tree photosynthesis and root respiration. Oecologia 127:305-308

Fahnestock JT, Povirk KL, Welker JM (2000) Ecological significance of litter redistribution by wind and snow in arctic landscapes. Ecography 23:623-631

Gaudinski JB, Trumbore SE, Davidson EA, Zheng SH (2000) Soil carbon cycling in a temperate forest: radiocarbon-based estimates of residence times, sequestration rates and partitioning of fluxes. Biogeochemistry 51:33-69

Gorham E (1991) Northern Peatlands: role in the carbon-cycle and probable responses to climatic warming. Ecol Appl 1:182-195

Henry GHR, Molau U (1997) Tundra plants and climate change: the international tundra experiment (ITEX). Glob Change Biol 3:1-9

IPCC (2007) Climate Change 2007: The physical science basis. Contribution of Working Group I to the fourth assessment report of the Intergovernmental Panel on Climate Change. Cambridge University Press, Cambridge

Jones MH, Fahnestock JT, Walker DA, Walker MD, Welker JM (1998) Carbon dioxide fluxes in moist and dry arctic tundra during season: responses to increases in summer temperature and winter snow accumulation. Arctic Alpine Res 30:373-380

Jorgenson MT, Racine CH, Walters JC, Osterkamp TE (2001) Permafrost degradation and ecological changes associated with a warming climate in central Alaska. Clim Change 48:551-579 
Jorgenson MT, Shur YL, Pullman ER (2006) Abrupt increase in permafrost degradation in Arctic Alaska. Geophys Res Lett 33:L23503

Mack MC, Schuur EAG, Bret-Harte MS, Shaver GR, Chapin FS (2004) Ecosystem carbon storage in arctic tundra reduced by long-term nutrient fertilization. Nature 431:440-443

McKane RB et al (1997) Climatic effects on tundra carbon storage inferred from experimental data and a model. Ecology 78:11701187

Michaelson GJ, Ping CL, Kimble JM (1996) Carbon storage and distribution in tundra soils of arctic Alaska. USA Arct Alp Res 28:414-424

Miller PC, Kendall R, Oechel WC (1983) Simulating carbon accumulation in northern ecosystems. Simulation 40:119-131

Neff JC et al (2006) Seasonal changes in the age and structure of dissolved organic carbon in Siberian rivers and streams. Geophys Res Lett 33

Osterkamp TE, Romanovsky VE (1999) Evidence for warming and thawing of discontinuous permafrost in Alaska. Permafrost Periglac Process 10:17-37

Ping CL et al (2008) High stocks of soil organic carbon in the North American Arctic region. Nat Geosci 1:615-619

Post WM, Pastor J, Zinke PJ, Stangenberger AG (1985) Global patterns of soil nitrogen storage. Nature 317:613-616

Robinson CH, Wookey PA, Parson AN, Welker JM, Callaghan TV, Press MC, Lee JA (1995) The response of plant litter decomposition, soil nutrient release and nitrogen mineralization to simulate climate change in a high arctic polar semi-desert and a subarctic dwarf shrub heath. Oikos 74:503-512

Romanovsky VE, Osterkamp TE (2000) Effects of unfrozen water on heat and mass transport processes in the active layer and permafrost. Permafrost Periglac Process 11:219-239

Schimel JP, Bilbrough C, Welker JA (2004) Increased snow depth affects microbial activity and nitrogen mineralization in two arctic tundra communities. Soil Biol Biochem 36:217-227

Schuur EAG et al (2008) Vulnerability of permafrost carbon to climate change: implications for the global carbon cycle. Bioscience 58:701-714

Schuur EAG, Vogel JG, Crummer KG, Lee H, Sickman JO, Osterkamp TE (2009) The effect of permafrost thaw on old carbon release and net carbon exchange from tundra. Nature 459:556-559

Serreze MC et al (2000) Observational evidence of recent change in the northern high-latitude environment. Clim Change 46:159-207

Shaver GR et al (1998) Biomass and $\mathrm{CO}_{2}$ flux in wet sedge tundras: responses to nutrients, temperature, and light. Ecol Monogr 68:75-97

Southon J et al (2004) The Keck Carbon Cycle AMS laboratory, University of California, Irvine: initial operation and a background surprise. Radiocarbon 46:41-49

Stuiver M, Polach HA (1977) Reporting of C-14 data: discussion. Radiocarbon 19:355-363
Sturm M et al (2005) Winter biological processes could help convert arctic tundra to shrubland. Bioscience 55:17-26

Tape K, Sturm M, Racine C (2006) The evidence for shrub expansion in Northern Alaska and the Pan-Arctic. Glob Change Biolo 12:686-702

Wahren CHA, Walker MD, Bret-Harte MS (2005) Vegetation responses in Alaskan arctic tundra after 8 years of a summer warming and winter snow manipulation experiment. Glob Change Biol 11:537-552

Walker MD et al (1999) Long-term experimental manipulation of winter snow regime and summer temperature in arctic and alpine tundra. Hydrol Process 13:2315-2330

Walker M, Wahren H, Ahlquist L, Alatolo J, Bret-Harte S, Calef M, Callaghan TV, Carroll A, Copass C, Epstein H, Henry G, Hollister R, Jonsdottír IS, Klein J, Magnusson B, Molau U, Oberbauer S, Rewa S, Robinson C, Shaver G, Suding K, Tolvanen A, Totland $\varnothing$, Turner PL, Tweedie C, Webber P, Wookey PA (2006) Plant community responses to experimental warming across the tundra biome. Proc Natl Acad Sci USA 103:1342-1346

Welker JM, Wookey PA, Parsons AN, Press MC, Callaghan TV, Lee JA (1993) Leaf carbon-isotope discrimination and vegetative responses of Dryas-octopetala to temperature and water manipulation in a high arctic polar semidesert, Svalbard. Oecologia $95: 463 \mathrm{c}-469 \mathrm{c}$

Welker JM, Molau U, Parsons AN, Robinson CH, Wookey PA (1997) Responses of Dryas octopetala to ITEX environmental manipulations: a synthesis with circumpolar comparisons. Glob Change Biol 3:61-73

Welker JM, Brown KB, Fahnestock JT (1999) $\mathrm{CO}_{2}$ flux in Arctic and alpine dry tundra: comparative field responses under ambient and experimentally warmed conditions. Arct Antarct Alp Res $31: 272-277$

Welker JM, Fahnestock JT, Jones MH (2000) Annual $\mathrm{CO}_{2}$ flux in dry and moist arctic tundra: field responses to increases in summer temperatures and winter snow depth. Clim Change 44:139-150

Welker JM, Fahnestock JT, Henry GHR, O'Dea KW, Chimner RA (2004) $\mathrm{CO}_{2}$ exchange in three Canadian High Arctic ecosystems: response to long-term experimental warming. Glob Change Biol 10:1981-1995

Welker JM, Fahnestock JT, Sullivan PF, Chimner RA (2005) Leaf mineral nutrition of arctic plants in response to warming and deeper snow in northern Alaska. Oikos 109:167-177

Wookey PA, Parsons AN, Welker JM, Potter JC, Callaghan TV, Lee JA, Press MC (1993) Comparative responses of subarctic and high arctic ecosystems to simulated climate change. Oikos 67:490-502

$\mathrm{Xu}$ XM et al (2007) Modifying a sealed tube zinc reduction method for preparation of AMS graphite targets: reducing background and attaining high precision. Nucl Instrum Methods Phys Res B 259:320-329 